\title{
An In-situ Study of Information Needs in Design-related Creative Projects
}

\author{
Yinglong Zhang, Rob Capra, Yuan Li \\ University of North Carolina at Chapel Hill \\ yinglongz@unc.edu,rcapra@unc.edu,yuanli@email.unc.edu
}

\begin{abstract}
A recent study found that search engines play an important role in supporting creative tasks that people encounter in everyday life [83]. However, little research has been conducted to understand how people use search engines and other information resources to support creative endeavors in their day-to-day work and life. To gain a deeper understanding, we conducted a diary study by asking eleven participants to record diary entries about their own designrelated creative projects over a two-week period. In this paper, we report the findings of our qualitative analysis of participants' diary entries and post-diary in-depth interviews. Specifically, we identified six types of information that were essential to design-related creative projects: procedural information, domain information, finished examples, tips/opinions/recommendations, information about specific topics, and inspiring/motivating information. For each type of information, we discuss participants' intents to use the information in their projects. We also describe challenges reported by our participants when they used search engines to address their information needs. Finally, we discuss implications of our findings for future research and the future design of search systems.
\end{abstract}

ACM Reference Format:

Yinglong Zhang, Rob Capra, Yuan Li. 2020. An In-situ Study of Information Needs in Design-related Creative Projects. In 2020 Conference on Human Information Interaction and Retrieval (CHIIR '20), March 14-18, 2020, Vancouver, BC, Canada. ACM, New York, NY, USA, 11 pages. https: //doi.org/10.1145/3343413.3377973

\section{INTRODUCTION}

Creativity and innovation are highly valued characteristics by societies and individuals. The importance of supporting humans' creativity through the use of technologies has been recognized by many scholars over the past decades. Seeking to develop tools to support creativity, researchers in human-computer interaction (HCI) and related fields have explored ways to understand creativity and to design creativity support tools (CSTs) [3, 19, 20, 2830, 32, 36, 39, 49, 58, 61, 67, 78]. However, as Frich and his colleagues [25] point out, much of the existing creativity-related $\mathrm{HCI}$ research has focused on new tools, often developed by the researchers themselves, and investigated in controlled experiments.

Permission to make digital or hard copies of all or part of this work for personal or classroom use is granted without fee provided that copies are not made or distributed for profit or commercial advantage and that copies bear this notice and the full citation on the first page. Copyrights for components of this work owned by others than the author(s) must be honored. Abstracting with credit is permitted. To copy otherwise, or republish, to post on servers or to redistribute to lists, requires prior specific permission and/or a fee. Request permissions from permissions@acm.org.

CHIIR '20, March 14-18, 2020, Vancouver, BC, Canada

(c) 2020 Copyright held by the owner/author(s). Publication rights licensed to ACM ACM ISBN 978-1-4503-6892-6/20/03 ..\$15.00

https://doi.org/10.1145/3343413.3377973
Frich et al. suggest that research should focus more effort on "studying in-vivo use of creativity support tools, not just the ones we build ourselves, but the ones that most creative practitioners employ in practice" [25, p. 1243]. The current research responds to this call.

Search engines are one of the most used tools on the internet. Given their widespread use, search engines are well-positioned to be excellent platforms for supporting users' creativity. Indeed, a recent survey study [83], found that search engines were the most frequently used tool in people's everyday creative tasks, but that they had limitations and drawbacks for particular creative stages (e.g. ideation). Considering these points, if search engines could be improved to better support different stages of users' creative tasks, a large number of people would benefit.

In the area of information search and retrieval, however, only a few efforts have been made to investigate how to design search systems and information tools to support creative tasks. Some studies have been conducted to understand and design methods to deliberately induce serendipity into search systems [5, 60, 74]. However, it should be noted that focusing on the "chance encounters" aspect of serendipity will not necessarily support creativity [2]. In the area of information seeking, interesting research has investigated people's information-based ideation behavior [50,51]. However, much of the prior research on creativity shows that generating and developing ideas is just one part of users' overall creative processes [65].

In the work presented in this paper, we seek to gain an understanding of how people use search engines and other information tools to support their everyday creative tasks and creative processes. To gain deep insights, we conducted a diary study to investigate and understand participants' in-situ search behaviors. To scope our study, we focused on design-related projects, which broadly refer to projects in which people try to design solutions to problems or challenges by using creative processes (e.g., design thinking). We recruited eleven participants, asked them to record diary entries about their own projects over a two-week period, and asked them follow-up questions in an final interview. We were particularly interested in getting a deep understanding of how people use search engines and other information resources to meet their information needs in designed-related creative projects. We were also interested in how the information they found was used to help their projects move forward.

Specifically, we address the following research questions:

- RQ1. What types of information do people need to support their design related creative projects? In RQ1, we looked at information needs from the perspective of "the nature of information" [9, p. 87]. Specifically, we were interested in understanding the types of information that people seek in their design-related projects. 
- RQ2. What information needs do people have during creative projects? What intents do they have to use the information they seek?

RQ2 investigated participants' intent to use the information that they find. In this question, we sought to gain a deeper understanding of people's information needs by investigating "what they use it for" [9, p. 87] in their projects.

- RQ3. What problems do people encounter when they attempt to address their information needs in creative projects?

RQ3 aimed to uncover the problems that people encounter when they look for the information that they need for their projects. Examining this research question helps us identify possible ways to improve search engines to better support people's design-related creative tasks.

\section{RELATED WORK}

\subsection{Creativity \& the creative process}

Research on creativity has largely been considered along two perspectives. In the sociocultural approach ("big-C"), scholars attempt to understand creative genius and identify which creative works might last forever [69]. Whereas the sociocultural approach ("bigC") assumes that only certain people can be creative, the individual approach ("little-c") looks more at everyday creativity which is seen as central to human survival and can be found in everyone [62] From the perspective of individualists, creativity is defined as "a new mental combination that is expressed in the world" [65, p.7]. In the work presented here, we focus on everyday creativity ("little-c"). Everyday creativity has been considered along four levels: doing, adapting, making, and creating (the highest level) [63].

Despite some disagreements on the definitions of creativity, there is a general agreement that creativity is a process. In 1926, Wallas [77] created one of the earliest creative process models by examining four different stages: preparation, incubation, illumination, and verification. Inspired by Wallas' work, other models emerged including Amabile's five-stage model [1], the Geneplore model [23], Mumford's eight-stage model [57], and Sawyer's integrated framework [65].

\subsection{Information needs}

In the area of information science, information needs have been explored from different perspectives [9, p. 81-85]: "seeking answers" (e.g., Taylor's typology of information needs [73]), "reducing uncertainty" (e.g., Belkin's hypothesis of the anomalous state of knowledge [6] and Kuhlthau's ISP stage framework [41]), and "making sense" (e.g., Dervin's sense-making theory [22]). Although the research noted above has considered information needs from different perspectives (e.g., subjective vs. objective), much research has investigated information needs based on three dimensions: "the nature of information", "why people seek", and "what they use it for" [9, p. 87]. In the context of information retrieval, research has also been conducted to understand how information needs trigger people to search for information using search systems (e.g., Ingwersen's integrated IS\&R research framework [34] and Cole's theory of information need for information retrieval [15]).
In the area of library science, several efforts have been made to understand the information needs of artists. For example, by interviewing four artists (a sculptor, painter, fiber artist, and metalsmith), Cobbledick [14] found that they had different kinds of information needs (e.g., inspiration, technical information, specific visual information, information about trends and events in the art world, and business information). Inspired by Cobbledick's work, other similar studies have been conducted to investigate the information seeking behaviors of artists $[16,24,76]$ and art librarians $[45,71]$. Regarding the limitations of the research aforementioned, Cowan [16] noted that all the studies focused on a particular group of people who worked in academia and who were library users. In this case, the library had been assumed to be the primary place where artists sought the information related to their work.

In the area of human-computer interaction (HCI), Sohn, Li, Griswold, and Hollan [70] developed a taxonomy of 16 broad information needs based on data analyzed from a diary study. They identified contextual factors that could influence users' information needs (time, activity, conversation, and location) in the context of mobile search. In an another diary study of mobile information needs, Church and Smyth [13] identified three sub-classes of information needs: local explicit, local implicit, and directions. In more recent work, Church et al. [12] ran a large-scale diary study and developed categories of daily information needs based on the taxonomy proposed by Dearman, Kellar, and Truong [21] including persons, organizations, offerings, events, environmental conditions, news\&trivia, finding, availability, and guidance.

\subsection{Search intents}

Search intent refers to the reasons for issuing a specific query ("why people search" [9, p. 87]). In prior research, many efforts have been made to understand and categorize users' search intent. For instance, Jansen, Booth, and Spink [35] conducted a large-scale log analysis and identified three types of search intents [35]: informational, navigational, and transactional. In more recent research, Mitsui and his colleagues summarized 20 different intentions in searching tasks $[55,56]$. Different from the aforementioned studies that primarily focus on investigating users' intents behind search queries in searching tasks, some research also seeks to examine intents behind people's information needs. For instance, Church and Smyth examined the intents behind mobile information needs and found that these intents not only involved achieving the goal of finding information about a topic, but also included the goal of managing people's own personal information [13].

\subsection{Information-based ideation behavior}

Information-based ideation behavior (IBI) is the process in which individuals integrate acquired knowledge with prior knowledge to seek a new understanding or to create new ideas [4]. Related to this, Kerne has noted that the finding and using of information can facilitate individuals in generating new ideas that can lead to creativity [37, 38]. In prior work, several efforts have been made to understand IBI in specific situations. For example, Makri and Warwick [51] examined how architects look for inspiration by seeking and using information on the Web. They highlighted 
the importance of supporting architects' information use behaviors, communication behaviors, and use of multimedia materials [51]. In a more recent study, Makri and his colleagues developed a framework to describe game designers' "information behavior undertaken specifically for the purpose of generating and developing ideas" [50, p.776]. Several specific types of information acquisition behavior (e.g., seeking, encountering, monitoring, examining, immersing, unblocking) and use behaviors (e.g., interpreting, collecting, externalizing, communicating) were identified.

\section{METHODS}

To investigate our research questions (RQ1-3), we conducted a diary study with participants who were focused on design-related projects. Different from survey and interviews that have been widely used to investigate artists and designers' information seeking behaviors [16, 24, 45, 54, 71, 76], diary studies can have high ecological value as they are carried out in situ and minimize the effects of observers and participants $[8,18]$. Additionally, the diary method is less likely to suffer from "recall" issues that have been found in surveys and interviews, considering that participants are asked to report events or information on a frequent basis in their diary entries. In this sense, a diary study is appropriate to deeply investigate information needs, because people can experience a variety of information needs throughout a day that may not be correctly recalled in an interview or survey. In this section, we describe our participants and recruiting, data collection, and data analysis methods.

\subsection{Participants and Recruiting}

We had several goals in recruiting. First and foremost, we wanted to recruit participants who had some creative experience and who were about to engage in a new creative project. We also established several selection criteria in advance of our recruiting: (1) participants should be familiar with creative processes; (2) their project should involve at least the ideation and test stages of the creative process, and ideally would involve additional stages; (3) the project should be flexible (e.g., no school projects or assignments that needed to meet certain requirements), (4) the project should involve looking for information on the web (e.g., painting a picture from memory might not involve any need to search for information), and (5) participants should be able to provide good written descriptions of their project work.

Our recruitment process included two parts: an initial screening questionnaire and a follow-up screening interview. We sent an invitation email with a link to the screening questionnaire to students at a large university in the United States during April 2019. In the questionnaire, we asked questions about students' background and the creative projects they planned to conduct in the near future (using open-ended questions that asked them to describe their projects). After a two-week period, 33 students submitted responses. Each of the responses was reviewed by our research team. After the first round review based on the criteria described earlier, 16 candidates were invited for individual 20-minute screening interviews. In the interviews, we asked questions about their project, what it involved, its timeline, and how they thought they might use online information resources during the project. All participants at this stage were compensated USD \$15 for completing the screening interview. Based on the data collected from screening questionnaires and interviews, the research team discussed each candidate and selected 15 participants to participate in the two-week diary study. All the participants met the selection criteria that we set in advance. We worked individually with each participant to select a two-week period for their participation. During the study, four participants dropped out within the first week of their participation. In total, 11 participants (see Table 1) completed their diary study sessions, and each was offered USD \$120 in compensation.

According to participants' answers in the screening questionnaire, the most common motivations for their creative projects were curiosity (6/11) and asserting their abilities or skills (2/11). According to Sander's framework of everyday creativity [63], these two motivations (curiosity and asserting their abilities or skills) are key drivers to the two highest levels of everyday creativity: the creating and making levels. This indicates that the projects that our participants brought to the diary study were prone to involve top levels of everyday creativity (creating and making levels).

Table 1: Participants and their projects

\begin{tabular}{|l|l|l|}
\hline P\# & Major & Project \\
\hline 2 & Arts & Making digital collages about a city after a hurricane \\
\hline 3 & Arts & Making a multiple color, layered woodblock print \\
\hline 4 & Arts & Creating a custom typography and poster \\
\hline 5 & Arts & Create abstract art using re-used technology \\
\hline 6 & Arts & Creating an abstract portrait of a family member \\
\hline 9 & Media & Internship projects in a creative agency \\
\hline 10 & Media & Writing nonfiction stories about sea level rise \\
\hline 11 & Nat. Sci. & Creating and selling her art works \\
\hline 12 & Psych. & Writing a manuscript for a historical fiction novel \\
\hline 13 & Psych. & Design a board game based on a family member's life \\
\hline 14 & Arts & Designing animations using Photoshop and Illustrator \\
\hline
\end{tabular}

\subsection{Data Collection}

Before each participant started their diary study, we scheduled an introductory meeting to explain the process of making diary entries and how to use the tools we designed to log their diary entries. The diary study included two parts: a two-week diary period followed by an in-depth interview (ranging from 90 minutes to 120 minutes).

To facilitate data collection and to preserve participants' privacy, we created a new, empty Firefox account for each participant. Participants were asked to log into the Firefox account and use the Firefox web browser to search for information when they were working on their projects. Participants were expected to work on their projects at least six days during the two week diary period so that we would have enough information to learn from them. Any day that they worked on their project, they were asked to fill out (1) a useful information form any time that they found information that helped move their project forward, and (2) a trouble form any time that they ran into a problem, obstacle, or frustration about finding information related to their project. For instance, to address RQ1 and RQ2, when participants reported each piece of useful information, they were asked to (1) provide the URL of the information found, and (2) explain how the information they found could help their project move forward. At the end of that day, 
participants were also asked to fill out a daily review questionnaire, which was designed to capture information that might be missing in the previous entries from the day. For example, to address RQ3, we asked two specific questions in the daily review questionnaire: "What were the biggest technical challenges for you today to work on your project?" and "What were the biggest nontechnical challenges for you today to work on your project?". The full text of all three of our diary entry forms is available at: https: //ils.unc.edu/searchstructures/resources/chiir2020_creative.pdf.

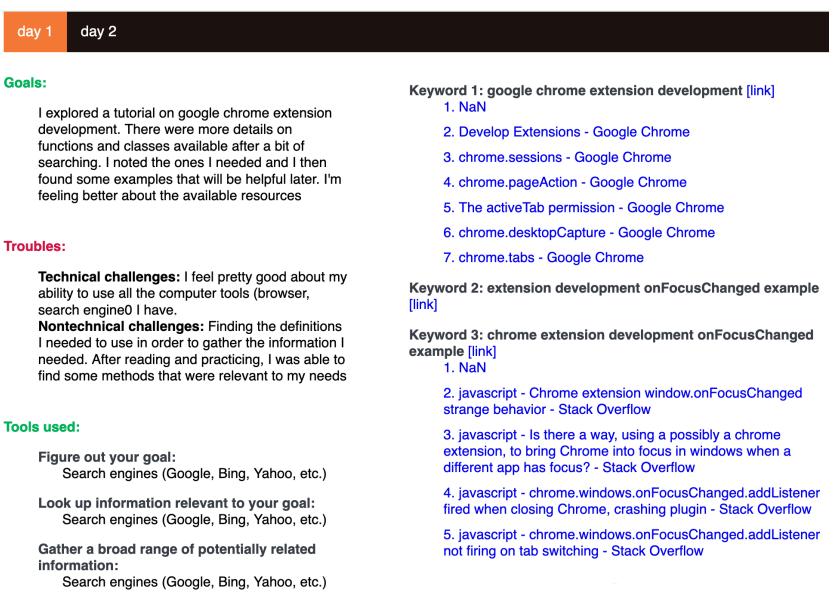

Figure 1: Interface of the custom-built tool to review diary entries. Selected diary entries are shown on the left, and logged search histories on the right (for privacy, data shown is not real participant data).

We scheduled an in-depth interview with each of the participants after their diary study period ended. Before each in-depth interview, we extracted the queries, titles of web pages, and URLs from the Firefox account history that the participant generated. A custom-built tool was designed to collate and display the logged data (queries, titles, and URLs) and the participant's diary entries during the in-depth interview (see Figure 1). During the interview, participants were asked to use their search history to recall what they did in their projects and to answer questions about how they used different tools and resources to support their creative processes. The moderator guide that we used for these interviews is available at the previously noted URL.

\subsection{Data Analysis}

All the in-depth interview recordings were transcribed before data analysis. We used the Dedoose qualitative analysis application to analyze diary entries (useful information form, trouble form, and daily review questionnaire) and the in-depth interview data. Following the workflow suggested by [43], the research team met multiple times during the qualitative data analysis processes. Two of the authors independently coded all the diary entries and resolved disagreement through multiple rounds of discussions. After finalizing the low-level codes, the research team had several meetings; after thorough discussion, we collapsed the low-level codes into themes and iteratively refined the themes (see Table 2 and Table 3 ).

\section{FINDINGS}

RQ1 asks, "What types of information do people need to support their design-related creative projects?" To address this question, we analyzed the dairy entries provided by participants on their useful information form. Based on their responses, we identified six types of information as shown in Table 2: (1) procedural knowledge (instructions), (2) domain knowledge, (3) finished examples, (4) tips/opinions/recommendations, (5) information about specific topics, and (6) inspiring/motivating information. We describe each of these in detail in later sub-sections.

RQ2 asks, "What information needs do people have during creative projects? What intents do they have to use the information they seek?" To address RQ2, we analyzed the usage intent behind each information need. Different from prior studies which have focused on "search intents" (intents to search for information) [55, 56], our study focuses on participants' intents to use information. For example, in the useful information form, instead of asking participants to explain why they searched for each piece of information, we asked them to describe how the information they found could help their project move forward. We choose this focus on usage intent in order to better understand how participants planned to use information they found in their projects. In our qualitative data analysis, we identified seven categories of usage intents (shown in Table 3): (1) to learn how to do something, (2) to seek inspiration, (3) for ideation (e.g., generate new ideas), (4) to evaluate and select ideas, (5) for project planning (e.g., conducting research to plan a project), (6) to make a purchasing decision, and (7) to keep motivated.

In the following sub-sections, we describe each of the six types of information (RQ1) and discuss how they were used to support participants' creative design process (i.e., the usage intents) (RQ2). We also discuss common roles that the usage intents played in each information need. Our final research question (RQ3), "What problems do people encounter?" is addressed in a separate subsection at the end of Section 4.

\subsection{Procedural knowledge}

Type of information. Procedural knowledge has been described as knowledge of "how to do it" (e.g, performing a specific skill or task) [53]. In our analysis, we considered procedural knowledge to refer to instructions or explanations about how to do something. Our participants described looking for a variety of types of procedural knowledge to support their creative projects. These included articles describing steps in a process, videos demonstrating how to do something, and online manuals/help for an application. Participants described two main genres for procedural knowledge: documents (e.g. articles, manuals), and videos. In addition, they distinguished how these two formats can differ in the amount of detail provided: "A demonstration [video] is they don't tell you steps, but they just show you... and when you look at steps, it's more [involved]. From here [articles], I can get definitive steps. They tell me exactly what they did versus a video... someone might not totally explain what they are doing [in videos].” [p3, interview]

Usage intents. Not surprisingly, procedural knowledge was largely associated with the usage intent to learn how to do something. Seven out of our 11 participants used procedural knowledge for this purpose. Procedural knowledge was also used to evaluate 
Table 2: We identified six types of information that participants reported in their useful information forms.

\begin{tabular}{|c|c|c|}
\hline Info Types & Description & Examples \\
\hline \multirow{3}{*}{$\begin{array}{l}\text { Procedural } \\
\text { knowledge } \\
\text { (instructions) }\end{array}$} & $\begin{array}{l}\text { User manual } \\
\text { (software or apps) }\end{array}$ & $\begin{array}{l}\text { "The page [Adobe user manual] I found told me how to create animations in Illustrator. This is something that I was previously } \\
\text { unaware of and although I knew it was possible to do, I struggled with it. I figured out from this page the file type I can export } \\
\text { the animation as." - P14 }\end{array}$ \\
\hline & Textual - steps & $\begin{array}{l}\text { "This [article] has step-by-step information through the prototype process as well as links to other related resources, like for } \\
\text { production. " - P13 }\end{array}$ \\
\hline & Videos - demonstration & $\begin{array}{l}\text { "The information [a video] I found was how to make a gradient for a block print. This will be helpful when executing the same } \\
\text { technique on my second layer of my print." - P3 }\end{array}$ \\
\hline $\begin{array}{l}\text { Domain } \\
\text { knowledge }\end{array}$ & $\begin{array}{l}\text { Declarative knowledge } \\
\text { of a domain }\end{array}$ & $\begin{array}{l}\text { "I wanted more information on Titans [domain knowledge related to mythology], especially what their equivalent to Mount } \\
\text { Olympus was. This determined my setting for the first section of my story, and helped me have a more accurate story." - P12 }\end{array}$ \\
\hline $\begin{array}{l}\text { Finished } \\
\text { Examples }\end{array}$ & $\begin{array}{l}\text { Finished examples of other } \\
\text { people's related work }\end{array}$ & $\begin{array}{l}\text { "This [a website] is an example of what I want one of my stories to look like, and it provides a good framework of how I can } \\
\text { shape my own ideas" - P10 }\end{array}$ \\
\hline $\begin{array}{l}\text { Tips/opinions/re } \\
\text { commen- } \\
\text { dations }\end{array}$ & $\begin{array}{l}\text { Tips, opinions, } \\
\text { recommendations about a } \\
\text { specific topic }\end{array}$ & $\begin{array}{l}\text { "I finally got my question answered... She [the YouTuber] recommended } 10 \text { prints of each design. This is helpful for me } \\
\text { because it allows me to have an idea of what I should buy, how many different types of prints I should have, and then how I am } \\
\text { going to price them" - P11 }\end{array}$ \\
\hline \multirow{4}{*}{$\begin{array}{l}\text { Information } \\
\text { about speicific } \\
\text { topic }\end{array}$} & About a person & $\begin{array}{l}\text { "I found this link after searching for contemporary collage artists or photographers. I think this has great leads to narrowing } \\
\text { down my artistic kindreds." - P2 }\end{array}$ \\
\hline & About a product or service & $\begin{array}{l}\text { "Google answered my question about the type of bit I should be purchasing in order to drill a hole through glass without } \\
\text { breaking it." - P5 }\end{array}$ \\
\hline & $\begin{array}{l}\text { About a specific business/ } \\
\text { organization/establishment }\end{array}$ & $\begin{array}{l}\text { "This information is about hydrogreography and planning for the City of [name], which will help inform my research and } \\
\text { discuss the city's history in my writing." - P10 }\end{array}$ \\
\hline & About a place or location & $\begin{array}{l}\text { "Google images of maps of [three states]. I'm thinking of making the game board that shape since those are the } 3 \text { states my } \\
\text { Dad has lived in, where we have family" - P13 }\end{array}$ \\
\hline $\begin{array}{l}\text { Inspiring } \\
\text { information }\end{array}$ & $\begin{array}{l}\text { Information that motivates } \\
\text { people }\end{array}$ & $\begin{array}{l}\text { "I mainly used this as visual inspiration for clothing and appearances, as well as a motivation booster, since the voice-over of } \\
\text { the myth is accompanied with classical art." - P12 }\end{array}$ \\
\hline
\end{tabular}

Table 3: We identified seven main intents to use the information that participants reported in their useful information forms.

\begin{tabular}{|c|c|c|}
\hline Intent & Description & Examples \\
\hline $\begin{array}{l}\text { Learn/figure out } \\
\text { how to do } \\
\text { something }\end{array}$ & $\begin{array}{l}\text { Figure out how to design } \\
\text { something, learn how to use a } \\
\text { new technique, feature, skill, or } \\
\text { tool, improve design } \\
\text { process/skill/technique, or use a } \\
\text { tool or technique }\end{array}$ & $\begin{array}{l}\text { "The page I found told me how to create animations in Illustrator. This is something that I was previously } \\
\text { unaware of and although I knew it was possible to do, I struggled with it. I figured out from this page the file type } \\
\text { I can export the animation as." - P14 }\end{array}$ \\
\hline Seek inspiration & $\begin{array}{l}\text { Process of collecting information } \\
\text { that might be used to generate } \\
\text { their own ideas. }\end{array}$ & $\begin{array}{l}\text { "lots of individual types of collectables that will be useful in the future when I'm trying to come up with specific } \\
\text { items and information about those items to include in the game." - P6 }\end{array}$ \\
\hline Ideation & $\begin{array}{l}\text { Process of creating their own } \\
\text { ideas by using all the information } \\
\text { that they already have }\end{array}$ & "[l] saw textures overlaid on type, [which] helped me integrate it into my project idea" - P4 \\
\hline $\begin{array}{l}\text { Idea evaluation } \\
\text { and/or selection }\end{array}$ & $\begin{array}{l}\text { Process of evaluating and/or } \\
\text { selecting idea(s) }\end{array}$ & $\begin{array}{l}\text { "I looked up more specifically Thai Kozo paper to find out more about it, and this resource had a great } \\
\text { description of the paper and it's qualities. This information reinforced my idea to use Thai Kozo paper in the } \\
\text { final print." - P3 }\end{array}$ \\
\hline Plan a project & $\begin{array}{l}\text { Process of developing a } \\
\text { design/project plan }\end{array}$ & $\begin{array}{l}\text { "I found information about one of the people I would like to talk to, and this brief summary of her work informs } \\
\text { me about her expertise and what I might like to ask her, which helps... preparing me for my interviews. " - P10 }\end{array}$ \\
\hline $\begin{array}{l}\text { Purchase } \\
\text { something }\end{array}$ & $\begin{array}{l}\text { Buying something that is needed } \\
\text { in the project }\end{array}$ & "This will help me move forward because I can purchase the gesso this week and start the painting. " - P6 \\
\hline Keep motivated & $\begin{array}{l}\text { Motivate themselves to continue } \\
\text { working on the project }\end{array}$ & $\begin{array}{l}\text { "...it [this video] inspired me to keep going. Working full time and doing other duties in just my normal life... is a } \\
\text { lot of work, and I haven't been dedicating a lot of time to... drawing" - P11 }\end{array}$ \\
\hline
\end{tabular}

and select ideas $(n=2)$, and for project planning $(n=2)$. In particular, videos helped facilitate the idea evaluation process in participants' projects. By watching videos, participants could predict and evaluate potential outcomes if a certain method or technique was used in their projects. For example, p3 mentioned in her diary: "I am now at the printing phase of my project and was curious on hand burnishing prints onto thicker paper. I know hand burnishing was ideal for thinner papers from prior knowledge, but found in this video that it can be just as successful on thicker weight paper. This is helpful to my project as I select a paper to use for the printing process."
The importance of procedural knowledge in design has also been identified in prior research which investigated how people searched "how-to" knowledge in craft projects [75].

\subsection{Domain knowledge}

Type of information. Domain knowledge is "the searcher's knowledge of the search subject or topic" [79, p. 247]. In our analysis, we found many examples of participants looking for information specifically related to the background, theory, and history of the topic 
of their creative project. For example, participants looked for information about mythology, art theory, game design theory, historical knowledge, and psychological theory related to their projects. Interestingly, most of the domain knowledge our participants sought was non-art and non-design related. Most of our participants had an art or design background and had sufficient knowledge about how to design something. The knowledge that participants searched for was more likely to be the new "domain" that they wanted to explore and include in their projects.

Usage intents. Domain knowledge was used by our participants for many reasons, including idea evaluation and selection $(n=5)$, learning how to do something $(n=3)$, inspiration $(n=2)$, ideation $(\mathrm{n}=2)$, and project planning $(\mathrm{n}=2)$. Our participants conveyed an important point related to the usage of domain knowledge: design is both object and experience. Many participants' projects were developed around a meaningful "story". To craft the stories behind their designs, participants searched for related domain knowledge help themselves understand and decide which stories they wanted to tell in their work. For instance, p6 created a portrait of her mother to give to her father as a gift. In her diary, she mentioned that she incorporated sunflowers in her painting to tell the story about her mother: "this website had an additional piece of information about the sunflower and it's ability to remove toxins from soil and its heliotropism and phototripism. Those terms mean the sunflower turns toward the sun ... I can use this knowledge to make the sunflowers turn toward my mother to symbolize her role in our family as the life giver and source of power."

We also observed that this "story craft" process itself can involve certain creative activities. For instance, in p12's project (a writing project), she searched for domain knowledge about Titans to figure out how to frame the first section of her story and help to write "a more accurate story". As she mentioned in her diaries, this domain knowledge also helped her combine ideas: "this [website] provides a more story-like account of some story beats in Prometheus's story, including some characterization and character motivation that strays from the other source I found. Because of this, I want to combine different aspects of the two since mythology is inherently collaboration with different stories". In another similar project, p10 searched for domain knowledge to help herself plan the project by gaining " $a$ solid basis in the science" because "a lot of [the] project is storytelling with science mixed in." Some participants also used domain knowledge to evaluate and test ideas. For instance, p13 searched knowledge about game mechanics and definitions to help herself "narrow down the kinds that might be best to include in" her game.

In the area of information search and retrieval, extensive research has been conducted to understand the role of domain knowledge in search tasks $[48,52,82]$. However, to the best of our knowledge, few studies have attempted to understand how people use domain knowledge to achieve their creative goals in their tasks or projects (e.g., story crafting).

\subsection{Finished Examples}

Type of information. Another type of information sought by our participants to support their creative tasks were examples of finished projects completed by other people. Finished examples can provide a tangible illustration of what a project using a particular technique might look like, or how it might function.
Usage intents. Our participants described using finished examples to learn how to do something $(n=5)$, to seek inspiration $(n=5)$, for ideation $(n=2)$, and for idea evaluation and selection $(n=3)$. For example, participants noted using examples to rule out options when they evaluated and selected ideas. As p6 wrote in her diary: "After doing some practice I decided that a watercolor portrait won't capture the details I want. I searched for and found images of watercolor people. I can move forward using this information because I was able to rule out what I thought might be the design choice".

Participants also used finished examples to seek inspiration by exploring and collecting other people's finished work $(n=5)$. These ideas could then serve as the raw materials for participants to generate ideas during their own ideation process [65, p. 114]. For example, p13 described: "[I] Googled 'illustrated map of [state name] USA' and found a cool vintage map in Google Images. [I] followed the link to this website that I then searched for similar styled maps for [other states]. They serve as inspiration...”

In addition to seeking inspiration, figuring out how to do something $(n=5)$ was another usage intent for which participants looked for finished examples. As p10 wrote in her diaries, "this [website] is an example of what I want one of my stories to look like, and it provides a good framework of how I can shape my own ideas into a tangible product".

A few participants $(n=2)$ also used finished examples to facilitate their ideation processes. For example, p6, mentioned in her diaries that while she painted the portrait of her mother, she searched for "girl on bike images that remind me of my Mom's picture" to help her "get an image in my mind of a combined pic with right pose".

In the field of information retrieval, providing support for finding finished examples has not been explored much outside the context of image search. However, researchers in HCI have recognized the critical role of examples in people's creative work and explored different ways to support using examples in creative processes [42, 47, 68, 72].

\subsection{Tips, opinions, and recommendations}

Type of information. Tips, opinions, and recommendations were another commonly sought type of information in our participants' creative projects. Similar to procedural knowledge, tips, opinions, and recommendations may include steps, instructions, or guidance to help participants perform a technique or use a tool in their projects. However, different from procedure knowledge, tips, opinions, and recommendations also include other people's experiences and reflections which provide participants additional insights.

Usage intents. Participants used tips, opinions, and recommendations to help figure out how to do something $(n=5)$, for idea evaluation and selection $(n=2)$, project planning $(n=2)$, to seek inspiration $(n=1)$, and for ideation $(n=1)$. For instance, $p 13$ found a blog about game mechanics that described various options and explained why they work well in different games. In her diary, p13 noted that these recommendations helped with "deciding what to include and why" in her game design.

Similar to the tips, opinions, or recommendations identified in our study, feedback can help people evaluate and select ideas in people's creative work. In the area of HCI, the role of feedback in creative work has also been investigated. Specifically, studies have been conducted to investigate how designers seek feedback 
from online design communities $[11,17,80]$. This is an interesting area for exploration in the context of supporting creative tasks and information seeking activities to support creative tasks.

\subsection{Information about a specific topic}

Type of information. Participants reported looking for information about specific topics (e.g., people, locations, products, services, tools) related to their projects.

Usage intents. Participants used the specific information they found for a variety of usage intents. These included using information about a person for inspiration $(n=3)$, using information about a business or organization to help with project planning $(n=3)$, and using inspiring information to keep motivated $(n=2)$.

Below, we discuss the specific information that our participants described and how they described using it.

About a person. Participants searched for information about a specific person's work, research experience, or background for different purposes related to their creative projects. Often, this information need was related to informing or motivating their creative design. In some cases, researching other people's work helped participants to narrow down the scope of their ideas (e.g., idea evaluation and selection). For instance, p2 searched for information about "contemporary collage artists or photographers" which provided "great leads to narrowing down my artistic kindreds". Participants also described searching for other designers or artists' work to help generate ideas (ideation). As p5 wrote in his diary, "This talk [by famous artist] generates new ideas for the production of my project and linked me to a multitude of different artists who work in a similar way".

Our participants also noted uses of the information related to a person that were tied to the specific requirements of a project. For instance, p6 searched Chopin's work because Chopin was her mother's favorite composer and she wanted to figure out how to "space the sunflowers to mimic a piece of Chopin music" in her painting (e.g., to learn/figure out how to do something). In another example, p10 looked for " a local expert on wetlands to answer some science-based questions" to give her "ideas/opportunities to make my infographics" (e.g., to seek inspiration).

About a product or service. Many participants' design-related projects involved using physical tools, software/apps, or materials to create something. Seeking information (e.g., price, properties, or quality) about a product or service helped participants make good design decisions for their creative activities (idea evaluation and selection). For example, p3 searched for information about the characteristics of "Kozo paper" to "reinforce my idea to use Thai Kozo paper in the final print". The descriptions of "gloss medium" also helped p6 to figure out "how to use it" to make "the bicycle to be shiny and man-made" in her painting (learn/figure out how to do something). In another case, p11 searched for product information to help plan out her project (e.g., making a business plan about "how I want my table to look", "what kind of things I can display", and "how I can display it"). In the same project, p11 also searched for several products to seek inspiration on "on how to package (which will go into pricing my items), and possibly sell them and make them look cute for other people wanting to buy them".
About a business/organizations and location/place. In some projects, participants searched for specific information about a business, organization, or location. For instance, p10 sought to write several narrative nonfiction stories about sea level rise, and searched for information about "hydrogreography and planning for the City of [cityname]" to help "inform my research and discuss the city's history" in her writing. In another example, p13 searched "maps of [three states]" to help design her game board because "those are the 3 states my Dad has lived in... where we have family..."

\subsection{Inspiring information}

Type of information. An interesting information need described by two of our participants was to look for inspiring (or motivating) information.

Usage intents. For instance, p11 noted that they searched for inspiring information to motivate themselves to continue working on their project: "while this video didn't really have any information about my project, it inspired me to keep going. This helped me in a way that motivated me to... keep working at my project and allowed me to come up with more ideas...". Similarly, p12 mentioned that she found information that would serve as "a motivation booster" to help her keep going on her project.

The effects of affective factors are not new to the research on creativity. Some efforts have been made to understand how people's emotions can influence their creative processes. Based on the the appraisal theory of emotion [26, 46, 59, 66], for instance, de Rooij et al. developed a framework to explain how emotions influence the execution of the idea generation process in people's creative work [20]. This is also an interesting area for future work related to search system support for creative tasks.

\subsection{Challenges}

Our third research question (RQ3) asks, "What problems do people encounter when they attempt to address their information needs in creative projects?" To identify problems and challenges that participants encountered, we analyzed diary entries on the daily review questionnaire and responses participants gave to questions during their in-depth interview. Below, we summarize our findings based on our qualitative analysis.

Challenges in searching for finished examples. As noted in Section 4.3, we found that participants looked for finished examples to seek inspiration in their projects. Although finished examples occur in different forms (e.g., articles, images, or videos), images were the primary resource that participants used to search for examples. Current search engines do a good job in helping people find a variety of images, but there is room for improvement, especially for supporting creative projects. For instance, it is challenging for people to quickly narrow down the scope of the images that they want to search. Particularly when people want to search for images that are related to design work and arts, search engines can encounter trouble providing high-quality, high-relevance results. Compared to some image resources (e.g., Pinterest, Instagram), our participants reported that results provided by existing search engines were too "general" and often lacked high-quality images created by artists or professionals. As one participant noted in the in-depth interview: "When you go look at Google images, they a lot of times will show... 
This is going to sound awful... people that don't make good art or good prints... versus Pinterest [where] there's people with talent... [type of art] is a very detail oriented process, so these are typically people that know what they're doing. This is very beautiful and labor intensive, so it's just more detailed..."

Another challenge related to searching finished examples is to track and save the images that have been already viewed. Different from reading articles, browsing pictures can be a fast-paced process, and people can browse a lot of images in a short time period. When using search engines to browse images, people may look at them without clicking them. That is to say; many of the viewed images may not have a specific entry in the browser history. For example, p16 noted that they downloaded images so that they could go back to review them later: "I find it so important to save the images since by scanning them a few days later they evoke different thoughts than the first time, so I save images I like to a file. I probably have 20 images now for this project". In this sense, it would help users to streamline their creative processes if search systems could be designed to make it easier to save and organize images without disrupting users' browsing flow.

In future research, more efforts are needed to develop search assistance tools for supporting people to track their search histories. Shneiderman has also noted that rich history-keeping feature can benefit discovers and innovators' structured or free-form thinking [67]. The saved tracking information in users' work trails of a project can support users to compare and modify the alternatives in the project [67].

Challenges in searching for procedural knowledge. Another challenge described by our participants was to find the exact procedural knowledge that they were looking for (e.g., instructions). Importantly, our participants were not amateurs, but rather, most had previous design/art training. That is to say, the "procedural knowledge" sought by our participants was less likely to involve introductory or general questions (e.g., "how to use photoshop", "how to paint"). Instead, our participants' questions were often very specific to a particular technique, feature, or skill. In this sense, existing commercial search engines may face challenges in providing information that is relevant in very specific ways due to biases in training search algorithms (e.g., ranking general results higher in a result list). As p14 wrote in her diaries: "I've found this seems to be an issue a lot. I don't think it's because my searches are wrong, I just think that there's so much that was related to what I wanted, but maybe not so much about the exact things I was hoping to find."

Challenges in searching tips, opinions, and recommendations. Searching for and making sense of tips, opinions, and recommendations can be very challenging, particularly when the information may be contradictory. As $\mathrm{p} 3$ pointed out in her in-depth interview, when she searched for recommendations about multilayer block printing, she felt confused because "there are a lot of different ways... and some people are like 'this is the best way' and other people are like 'Oh, no. Don't use this way'."

\section{DISCUSSION AND IMPLICATIONS}

We conducted an in situ diary study with 11 participants to investigate people's information needs in their own creative projects over a two-week period. At the end of the two-weeks, we engaged each participant in a detailed retrospective interview to gain deeper insights into their information seeking in the context of their creative project. In this section, we summarize our main findings, discuss them in the context of related work, and describe implications.

In RQ1, we examined what types of information people need to support creative projects. Through qualitative analysis of participants' diary entries, we identified six main types of information that our participants described using in their creative tasks: 1) procedural knowledge, 2) domain knowledge, 3) finished examples, 4) recommendations, 5) specific information, and 6) motivating information. In their classic work on information seeking and use, Byström and Järvelin [7] outline three categories of information: problem information (properties of the problem), domain information (facts, concepts, and theories in the problem domain), and problem-solving information (how to solve problems) [7, p.195196]. Relating the information types our participants described to Byström and Järvelin's classifications, we find that domain information maps well to domain knowledge and specific information. Problem-solving information includes procedural knowledge, recommendations, and could also involve finished examples and motivating information.

Several of the information types we identified have also been observed in previous studies of daily information needs. For example, Church et al. [12] and Dearman et al. [21] reported that their participants had daily information needs for specific information (e.g., about persons, businesses, organizations) and guidance (e.g., recommendations and advice). However, in our participants' on-going creative projects, they described additional needs for examples, procedural, domain, and motivating information. This suggests that creative tasks involve similar types of information that people need in daily life, but also require additional types of information to support the on-going and creative aspects of the task.

We also identified specific illustrations of how different types of information are applied in a creative process. For example, when people design something, they need to generate ideas, externalize them, and transform them into objects by using different tools or techniques. In the ideation process, examples of finished projects play an essential role in helping to collect and generate design ideas. When people seek to externalize and instantiate their ideas, procedural knowledge and tips, opinions, and recommendations can help facilitate the process. Additionally, creative projects require a great amount of mental effort, which led some of our participants to seek motivating information to keep working on their projects.

In RQ2, we examined how participants' information needs in creative projects are connected to their intents to use the information they find. Through qualitative analysis, we identified seven categories of usage intents: 1) to learn to do something, 2) to seek inspiration, 3) for ideation, 4) to evaluate ideas, (5) for project planning, (6) to make a purchasing decision, and (7) to keep motivated. Several of these usage intents are common to other task types (e.g., learning to do something, planning, decision-making). However, seeking inspiration, ideation, and evaluating ideas are particularly characteristic of creative tasks and are associated with use cases that current search systems are not well-equipped to support. For uses such as ideation and seeking inspiration, the searcher's goal is often to generate new ideas. Prior work has considered dimensions of this. For example, in Belkin's ASK [6] and Dervin's sense-making 
model [22], new ideas can be possible outcome of information use. Understanding information use in the context of ideation has also been explored by Makri et al. [50]. Furthermore, uses such as inspiration and ideation distrupt traditional IR notions of relevance [64]. For example, when engaged in ideation, "relevant" results might be more divergent than convergent. Future work should further examine relevance in the context of creative processes.

Our findings illustrate how participants used the information they found to "create something" and demonstrate that understanding the intents for using information can help us better support users' information needs. We also note that the same information can be used for different reasons in different contexts. This emphasizes that when we study information needs, it is necessary to investigate them in context. By gaining an understanding of the usage intents for searches that are part of creative tasks, we can: (1) better model a range of information seeking behaviors, and (2) inform the design of future search systems.

In RQ3, we investigated the types of problems and challenges people encounter when attempting to address their information needs in creative projects. We found our participants encountered challenges when they used search engines to look for finished examples, tips/opinions/recommendations, and procedural knowledge. Below, we discuss implications of these challenges for the future design of search systems.

Implications for the future design of search systems. As mentioned in Section 4.7, one of the main challenges our participants reported was having trouble finding the exact information they sought to support their creative projects (especially in terms of procedural information). Based on our observations, there appear to be three main roots of this problem.

First, people do not have much control over the scope of the information returned by current search engines. Query modification is the primary way that users can alter the scope in many systems. However, generating a high-quality, high-precision query is not always an easy job. For instance, as p10 stated: "The biggest technical challenge was figuring out how to be both specific and broad in my search terms, because I wanted to gather a wide range of information but still have it be relevant to my topic."

Second, most current search engines do not give people an easy way to specify their own relevance criteria. Instead, relevance criteria are inferred by machine learning and ranking algorithms. In addition, users' queries may be under-specified and/or algorithms be mis-aligned to particular users' needs. Based on our observations, these issues are especially pronounced in searches to support creative needs such as inspiration, ideation, and idea evaluation.

Third, search engines can have difficult time inferring users' existing knowledge about a topic, which can have a large influence their relevance judgments $[31,44,84]$. For example, p14 noted in their diary, "...sometimes it was hard to find the answers to my specific questions. I wanted to find out how to copy/paste a layer onto a new layer, but I kept getting results on how to copy and paste onto the same layer... which I already knew how to do."

Future solutions might consider additional ways to "put users in the loop" and further leverage social- and user-contributed annotations. For example, p14 noted, "[on Pinterest] I'll add information so that the image is more accurate when somebody else searches it...
I'll go in, find the title and the year... Not only for myself but so that somebody else could search it using those key words."

Participants also noted their needs to get feedback about their projects. Participants primarily described two ways to get feedback regarding their work. To get direct feedback, participants mainly used social media apps to ask their friends, family, and colleagues to provide comments or suggestions on their ideas and work. For indirect feedback, participants searched for tips/options/ recommendations that could be analogous to their work and used them to help with evaluating ideas. Few efforts have been made to understand how to support people to easily find $\boldsymbol{u} \boldsymbol{s e f u l}$ tips/options/ recommendations for creative tasks. To achieve the goal, search systems need to learn how to do analogy mining and provide "analogically relevant results". This could also benefit searches for procedural knowledge. Related work in HCI may inform future research on this topic [10, 27, 33, 40, 81].

Limitations: As with all research, our study has limitations. Our sample of participants were all recruited from a university population and many were focused on physical art projects. Future work should explore the search needs and behaviors of people working in other creative domains.

\section{CONCLUSION}

In this paper, we conducted an in-situ study to learn about people's information needs in their design-related projects and the challenges they encountered. Seeking to gain a deep understanding we investigated participants' reports from two perspectives: "the nature of information" and "what they use it for" [9, p. 87]. Based on our qualitative analysis, we identified seven different types of information sought by our participants, including procedural knowledge (instructions), domain knowledge, finished examples, tips/opinions/recommendations, information about specific topics, and inspiring/motivating information. Additionally, we identified seven different usage intents (e.g., learning how to do something, seeking inspiration, ideation, evaluating and selecting ideas, project planning, making a purchasing decision, and keeping motivated.). In the diary study, our participants described their challenges when they used search engines to look for finished examples, procedural knowledge, and recommendations. The results of our exploratory research provide implications for future research on information needs and intents as well as future design of search engines.

Our in-situ study provided us an excellent opportunity gain insights into how people use search engines to support their creativity in their own projects and environments. The findings of our study suggest that supporting searches during creative tasks may involve providing results that go beyond traditional IR notions of ranking and relevance. Understanding how to present search results that will inspire and stimulate creativity in users is a challenging problem that will require additional research.

\section{ACKNOWLEDGEMENTS}

We thank our participants for their insightful diary entries and interviews, and for their inspiring creativity. This material is based upon work supported by the National Science Foundation under Grant No. 1552587. 


\section{REFERENCES}

[1] Teresa M Amabile. 1988. A model of creativity and innovation in organizations. Research in organizational behavior 10, 1 (1988), 123-167.

[2] Paul André, m.c. Schraefel, Jaime Teevan, and Susan T Dumais. 2009. Discovery is Never by Chance: Designing for (Un)Serendipity. In $C \& C^{\prime} 09$. ACM, New York, NY, USA, 305-314.

[3] Sharon Bailin. 2012. Achieving extraordinary ends: An essay on creativity. Springer Science \& Business Media.

[4] Marcia J Bates. 2010. Information behavior. In Encyclopedia of library and information sciences. 2381-2391.

[5] Russell Beale. 2007. Supporting serendipity: Using ambient intelligence to augment user exploration for data mining and web browsing. INT f HUM-COMPUT ST 65, 5 (2007), 421-433.

[6] Nicholas J Belkin. 1980. Anomalous states of knowledge as a basis for information retrieval. Canadian journal of information science 5, 1 (1980), 133-143.

[7] Järvelin-K. Byström, K. 1995. Task complexity affects information seeking and use. INFORM PROCESS MANAG 31, 2 (1995), 191-213.

[8] Scott Carter and Jennifer Mankoff. 2005. When participants do the capturing the role of media in diary studies. In CHI '05. ACM, 899-908.

[9] Donald O Case. 2012. Information Needs and Information Seeking. In Looking for Information: A Survey of Research on Information Seeking, Needs, and Behavior (third edition). Bingley, UK : Emerald Group Pub. Ltd., San Diego, CA, US

[10] Joel Chan, Joseph Chee Chang, Tom Hope, Dafna Shahaf, and Aniket Kittur. 2018 SOLVENT: A Mixed Initiative System for Finding Analogies between Research Papers. PACM HCI '18 2, CSCW (2018), 31.

[11] Joel Chan, Steven P. Dow, and Christian D. Schunn. 2015. Do the best design ideas (really) come from conceptually distant sources of inspiration? Design Studies 36 (2015), 31 - 58.

[12] Karen Church, Mauro Cherubini, and Nuria Oliver. 2014. A large-scale study of daily information needs captured in situ. TOCHI 21, 2 (2014), 10.

[13] Karen Church and Barry Smyth. 2009. Understanding the Intent Behind Mobile Information Needs. In IUI '09. ACM, New York, NY, USA, 247-256. https://doi. org/10.1145/1502650.1502686

[14] Susie Cobbledick. 1996. The information-seeking behavior of artists: Exploratory interviews. The Library Quarterly 66, 4 (1996), 343-372.

[15] Charles Cole. 2011. A theory of information need for information retrieval that connects information to knowledge. FASIST 62, 7 (2011), 1216-1231.

[16] Sandra Cowan. 2004. Informing visual poetry: Information needs and sources of artists. Art Documentation: Fournal of the Art Libraries Society of North America 23, 2 (2004), 14-20.

[17] Patrick A. Crain and Brian P. Bailey. 2017. Share Once or Share Often?: Exploring How Designers Approach Iteration in a Large Online Community. In $C \& C 17$. ACM, New York, NY, USA, 80-92. https://doi.org/10.1145/3059454.3059476

[18] Mary Czerwinski, Eric Horvitz, and Susan Wilhite. 2004. A diary study of task switching and interruptions. In CHI '04. ACM, 175-182.

[19] Nicholas Davis, Holger Winnemöller, Mira Dontcheva, and Ellen Yi-Luen Do. [n.d.]. In $C \& C$ ' 13 .

[20] Alwin de Rooij, Philip J Corr, and Sara Jones. 2015. Emotion and creativity: Hacking into cognitive appraisal processes to augment creative ideation. In $C \& C$. ACM, 265-274.

[21] David Dearman, Melanie Kellar, and Khai N Truong. 2008. An examination of daily information needs and sharing opportunities. In CSCW' 08. ACM, 679-688.

[22] Brenda Dervin. 1998. Sense-making theory and practice: an overview of user interests in knowledge seeking and use. f. Knowl. Manag. 2, 2 (1998), 36-46.

[23] Ronald A Finke, Thomas B Ward, and Steven M Smith. 1992. Creative cognition Theory, research, and applications. The MIT Press, Cambridge, MA, US.

[24] Polly Frank. 1999. Student artists in the library: an investigation of how they use general academic libraries for their creative needs. The fournal of Academic Librarianship 25, 6 (1999), 445-455.

[25] Jonas Frich, Michael Mose Biskjaer, and Peter Dalsgaard. 2018. Twenty Years of Creativity Research in Human-Computer Interaction: Current State and Future Directions. In Proceedings of the 2018 Designing Interactive Systems Conference. ACM, 1235-1257.

[26] N H Fridja, A Ortony, J Sonnemans, and G L Clore. 1992. The complexity of intensity: Issues concerning the structure of emotion intensity. Emotion (1992), 60-89.

[27] Karni Gilon, Joel Chan, Felicia Y Ng, Hila Liifshitz-Assaf, Aniket Kittur, and Dafna Shahaf. 2018. Analogy mining for specific design needs. In CHI '18. ACM, 121.

[28] François Guimbretière, Maureen Stone, and Terry Winograd. 2001. Fluid interaction with high-resolution wall-size displays. In UIST '01. ACM, 21-30.

[29] Raja Gumienny, Lutz Gericke, Matthias Wenzel, and Christoph Meinel. 2013 Supporting creative collaboration in globally distributed companies. In $C S C W$ '13. ACM, 995-1007.

[30] Joshua Hailpern, Erik Hinterbichler, Caryn Leppert, Damon Cook, and Brian P Bailey. 2007. TEAM STORM: demonstrating an interaction model for working with multiple ideas during creative group work. In Proceedings of the 6th ACM SIGCHI Conference on Creativity \& Cognition. ACM, 193-202.
[31] Stephen P Harter. 1992. Psychological relevance and information science. FASIST 43, 9 (1992), 602-615

[32] Otmar Hilliges, Lucia Terrenghi, Sebastian Boring, David Kim, Hendrik Richter, and Andreas Butz. 2007. Designing for collaborative creative problem solving. In C\&C '07. ACM, 137-146.

[33] Tom Hope, Joel Chan, Aniket Kittur, and Dafna Shahaf. 2017. Accelerating innovation through analogy mining. In SIGKDD '17. ACM, 235-243.

[34] Peter Ingwersen and Kalervo Järvelin. 2005. The Turn: Integration of Information Seeking and Retrieval in Context. Springer Netherlands, Dordrecht, 259-311.

[35] Bernard J Jansen, Danielle L Booth, and Amanda Spink. 2007. Determining the user intent of web search engine queries. In WWW'07. ACM, 1149-1150.

[36] Andruid Kerne, Nic Lupfer, Rhema Linder, Yin Qu, Alyssa Valdez, Ajit Jain, Kade Keith, Matthew Carrasco, Jorge Vanegas, and Andrew Billingsley. 2017. Strategies of Free-Form Web Curation: Processes of Creative Engagement with Prior Work. In $C \& C$ '17. ACM, 380-392.

[37] Andruid Kerne, Steven M Smith, Eunyee Koh, Hyun Choi, and Ross Graeber. 2008. An experimental method for measuring the emergence of new ideas in information discovery. INT 7 HUM COMPUT INTERACT 24, 5 (2008), 460-477.

[38] Andruid Kerne, Andrew M Webb, Steven M Smith, Rhema Linder, Nic Lupfer, Yin Qu, Jon Moeller, and Sashikanth Damaraju. 2014. Using metrics of curation to evaluate information-based ideation. TOCHI 21, 3 (2014), 14.

[39] Joy Kim, Maneesh Agrawala, and Michael S Bernstein. 2017. Mosaic: Designing Online Creative Communities for Sharing Works-in-Progress. In CSCW' 17. ACM, 246-258.

[40] Aniket Kittur, Lixiu Yu, Tom Hope, Joel Chan, Hila Lifshitz-Assaf, Karni Gilon, Felicia Ng, Robert E Kraut, and Dafna Shahaf. 2019. Scaling up analogical innovation with crowds and AI. PNAS 116, 6 (2019), 1870-1877.

[41] Carol C Kuhlthau. 1991. Inside the search process: Information seeking from the user's perspective. FASIST 42, 5 (1991), 361-371.

[42] Chinmay Kulkarni, Steven P. Dow, and Scott R. Klemmer. 2014. Early and Repeated Exposure to Examples Improves Creative Work. Springer International Publishing, Cham, 49-62.

[43] Bruce L Berg. 2001. Qualitative research methods for the social sciences. Pearson Boston, Boston, MA, USA

[44] F Wilfred Lancaster. 1979. Information retrieval systems; characteristics, testing and evaluation. In Information Sciencies Series. John Wiley \& Sons.

[45] Sara Shatford Layne. 1994. Artists, art historians, and visual art information. The reference librarian 22, 47 (1994), 23-36.

[46] Richard S Lazarus. 1991. Cognition and motivation in emotion. American psychologist 46, 4 (1991), 352.

[47] Brian Lee, Savil Srivastava, Ranjitha Kumar, Ronen Brafman, and Scott R Klemmer. 2010. Designing with interactive example galleries. In CHI '10. ACM, 2257-2266.

[48] Jingjing Liu, Chang Liu, and Nicholas J Belkin. 2016. Predicting information searchers' topic knowledge at different search stages. FASIST 67, 11 (2016), 2652-2666.

[49] Kurt Luther, Jari-Lee Tolentino, Wei Wu, Amy Pavel, Brian P Bailey, Maneesh Agrawala, Björn Hartmann, and Steven P Dow. 2015. Structuring, aggregating, and evaluating crowdsourced design critique. In CSCW' 15 . ACM, 473-485.

[50] Stephann Makri, Tsui-Ling Hsueh, and Sara Jones. 2019. Ideation as an Intellectual Information Acquisition and Use Context: Investigating Game Designers' Information-Based Ideation Behavior. FASIST 70, 8 (2019), 775-787.

[51] Stephann Makri and Claire Warwick. 2010. Information for inspiration: Understanding architects' information seeking and use behaviors to inform design. JASIST 61, 9 (2010), 1745-1770.

[52] Jiaxin Mao, Yiqun Liu, Noriko Kando, Min Zhang, and Shaoping Ma. 2018. How Does Domain Expertise Affect Users' Search Interaction and Outcome in Exploratory Search? TOIS 36, 4 (2018), 42.

[53] Robert McCormick. 1997. Conceptual and Procedural Knowledge. INT J TECHNOL DES ED 7, 1 (Jan 1997), 141-159.

[54] Ann Medaille. 2010. Creativity and craft: the information-seeking behavior of theatre artists. FDoc 66, 3 (2010), 327-347.

[55] Matthew Mitsui, Jiqun Liu, Nicholas J. Belkin, and Chirag Shah. 2017. Predicting Information Seeking Intentions from Search Behaviors. In SIGIR '17. ACM, New York, NY, USA, 1121-1124.

[56] Matthew Mitsui, Chirag Shah, and Nicholas J Belkin. 2016. Extracting information seeking intentions for web search sessions. In SIGIR '16. ACM, 841-844.

[57] Michael D Mumford, Michele I Mobley, Roni Reiter Palmon, Charles E Uhlman, and Lesli M Doares. 1991. Process analytic models of creative capacities. Creativity Research fournal 4, 2 (1991), 91-122.

[58] Kumiyo Nakakoji, Yasuhiro Yamamoto, and Atsushi Aoki. 2002. Interaction design as a collective creative process. In $C \& C^{\prime} 02$. ACM, 103-110.

[59] Alex Osborn. 1995. Applied Imagination-Principles and Procedures of Creative Writing. Read Books Ltd.

[60] Ataur Rahman and Max L Wilson. 2015. Exploring opportunities to facilitate serendipity in search. In SIGIR '15. ACM, 939-942.

[61] Mitchel Resnick. 2007. All I really need to know (about creative thinking) I learned (by studying how children learn) in kindergarten. In $C \& C^{\prime}$ '07. ACM, 1-6. 
[62] Ruth Richards. 2010. Everyday creativity: Process and way of life-Four key issues. In The Cambridge handbook of creativity. Cambridge University Press, New York, NY, US, 189-215.

[63] Liz Sanders and Pieter Jan Stappers. 2012. Convivial design toolbox: Generative research for the front end of design. BIS, Amsterdam.

[64] T. Saracevic. 2007. Relevance: A review of the literature and a framework for thinking on the notion in information science. Part III: Behavior and Effects of Relevance. FASIST 58, 13 (2007), 2126-2144.

[65] R Keith Sawyer. 2011. Explaining creativity: The science of human innovation. Oxford University Press, New York, NY, US.

[66] Klaus R Scherer. 2001. Appraisal considered as a process of multilevel sequential checking. In Appraisal processes in emotion: Theory, methods, research. Oxford University Press, New York, NY, US, 92-120

[67] Ben Shneiderman. 2007. Creativity support tools: Accelerating discovery and innovation. Commun. ACM 50, 12 (2007), 20-32.

[68] Pao Siangliulue, Kenneth C. Arnold, Krzysztof Z. Gajos, and Steven P. Dow. 2015. Toward Collaborative Ideation at Scale: Leveraging Ideas from Others to Generate More Creative and Diverse Ideas. In CSCW '15. ACM, New York, NY, USA, 937-945.

[69] D K Simonton. 2000. Creativity. Cognitive, personal, developmental, and social aspects. Am Psychol 55, 1 (2000), 151-158.

[70] Timothy Sohn, Kevin A. Li, William G. Griswold, and James D. Hollan. 2008. A Diary Study of Mobile Information Needs. In CHI '08. ACM, New York, NY, USA, 433-442.

[71] Deirdre C Stam. 1995. Artists and art libraries. Art libraries journal 20, 2 (1995), 21-24.

[72] Amanda Swearngin, Mira Dontcheva, Wilmot Li, Joel Brandt, Morgan Dixon, and Andrew J. Ko. 2018. Rewire: Interface Design Assistance from Examples. In CHI '18. ACM, New York, NY, USA, Article 504, 12 pages.
[73] Robert S Taylor. 1968. Ouestion-Negotiation and Information Seeking in Libraries. College \& Research Libraries 29, 3 (1968), 178-194.

[74] Elaine G Toms. 2000. Serendipitous Information Retrieval. In Proceedings of DELOS Workshop 2000, Vol. 1968.

[75] Cristen Torrey, Elizabeth F Churchill, and David W McDonald. 2009. Learning how: the search for craft knowledge on the internet. In CHI. ACM, 1371-1380.

[76] Carol Van Zijl and Elizabeth M Gericke. 2001. Methods used by South African visual artists to find information. Mousaion 19, 1 (2001), 3-24.

[77] G Wallas. 1926. The art of thought. J. Cape, London.

[78] Huaxin Wei and Betty Durango. 2017. Beyond Level Blueprints: Visualizing the Progression of Emotion and Narrative Driven Games. In Proceedings of the 2017 ACM SIGCHI Conference on Creativity and Cognition. ACM, 171-183.

[79] Barbara M Wildemuth. 2004. The effects of domain knowledge on search tactic formulation. FASIST 55, 3 (2004), 246-258.

[80] Anbang Xu and Brian Bailey. 2012. What Do You Think?: A Case Study of Benefit, Expectation, and Interaction in a Large Online Critique Community. In CSCW '12'. ACM, New York, NY, USA, 295-304. https://doi.org/10.1145/2145204.2145252

[81] Lixiu Yu, Robert E Kraut, and Aniket Kittur. 2016. Distributed analogical idea generation with multiple constraints. In CSCW' 16. ACM, 1236-1245.

[82] Xiangmin Zhang, Jingjing Liu, Michael Cole, and Nicholas Belkin. 2015. Predicting users' domain knowledge in information retrieval using multiple regression analysis of search behaviors. FASIST 66, 5 (2015), 980-1000.

[83] Yinglong Zhang and Robert Capra. 2019. Understanding How People Use Search to Support Their Everyday Creative Tasks. In CHIIR '19. Association for Computing Machinery, New York, NY, USA, 153-162.

[84] Yinglong Zhang, Jin Zhang, Matthew Lease, and Jacek Gwizdka. 2014. Multidimensional Relevance Modeling via Psychometrics and Crowdsourcing. In SIGIR '14. ACM, New York, NY, USA, 435-444. 